\title{
FINDING THE LOGIC OF LOCATION: AN ANALYSIS OF THE DISTRIBUTION PATTERN OF URBAN ACTIVITIES IN THE CITY OF COLOMBO WITH SPACE SYNTAX
}

\author{
MUNAISNGHE J. N. ${ }^{1} \&$ BANDARA A. ${ }^{2}$ \\ ${ }^{1}$ University of Moratuwa, Katubedda, Sri Lanka \\ ${ }^{2}$ CHEC Port City (Pvt) Ltd, Colombo, Sri Lanka \\ 1jagathnm@uom.lk, ${ }^{2}$ toaruna@gmail.com
}

\begin{abstract}
The self-organized order of the types, scales, and locations of different activities in urban areas has throughout been a matter of concern for planning. In order to regulate 'unplanned' distribution of activities in urban areas, planning authorities used different tools, of which zoning is still the most popular. However, except under heavily regimented conditions, zoning has continuously failed to withstand the forces that empowered urban activities to find their preferred locations in an urban area. Hence, planners need more strategic approaches than conventional methods in order to deal with the location dynamics of urban activities. In this regard, a comprehensive understanding on space appropriation by urban activities and the methods in which such understanding can be effectively integrated into planning strategies, are essential in planners. In a context where the available theories were limited in serving for this purpose, the Space Syntax method provides planners with a more convincing method to analyze and simulate spatial dynamics of urban areas, relating to 'spatial integration', which is an attribute that emerges from the overall configuration of the physical environment. Using this method, this study explored the potential relationship between the location choices of different urban activity types, and the level of spatial integration of their current locations within the core area of the city of Colombo.
\end{abstract}

Keywords: Spatial Integration, Location Choices, Appropriation, Urban Activities

\section{Introduction}

The pattern of distribution of formal and informal urban activities such as trade stalls, shopping centers, warehouses, administrative institutions, health and education facilities, restaurants and food outlets, entertainment centers, etc., in urban areas, be them cities or small towns, have throughout been a matter of interest to urban planners. In one front these activities cause externalities, which are internalized by other sets of activities and thereby cause a chain effect of agglomeration, enabling a shift of land uses in the respective urban locality. In another front, they attract pedestrian and vehicular traffic, thereby resulting in situations such as congestion and crowding. Moreover, they directly impact dominant land uses and property values and thereby facilitate social and cultural shifts, gentrification and the marginalization of certain communities. For all these valid reasons, formal urban planning and design interventions attempt to take control of the location decisions of different activities in urban areas.

However, planning controls are often contested by urban activities, more precisely by the firms operating those activities, because of the inherent differences between the objective functions of urban planning and business operations. Thus, a wide gap is apparent between the understanding of planners on the location attributes appropriate for urban activities and the preferences of the firms who operate them. Complaints and concerns related to the 'compatibility' of the uses are increasingly common in many urban areas, despite the regulatory measures enforced by the authorities. This situation, in a way, reflects the limitations of conventional authoritative approaches in urban planning, where planners are compelled to play more of a 'policing' role rather than a 'facilitator' role, and therefore, the necessity of more strategic interventions, than what is in practice now, to guide developments in urban areas towards desired futures. One of the most important requirements for planners in this regard is a comprehensive understanding of the spatial dynamics that govern the location choices of urban activities, which could be effectively integrated into workable planning strategies.

In this light, this study explores the potential relationship between spatial attributes surging from the overall configuration of a physical environment and the location choices of urban activities. The study is carried out in the core area of the City of Colombo, adopting the Space Syntax method. 


\section{Background}

Cities and towns, evolving freely with no formal regulatory interventions, usually result in bustling urban centers with multiple uses, high densities and crowded streets. The ongoing situation in these intensely developing built environments, characterized by heavy motor and pedestrian traffic flows, a complementary mix of uses and high densities, was regarded as 'problematic' by administrators as well as scholars since the late 19th century. It was in this background that modern planning emerged as a new specialty, and therefore, resistance towards self-organized order of urban activities is embodied in the core values of urban planning. Therefore, the 'incompatibilities' in the use of land and space by different activities, has been addressed by different tools, of which 'zoning' has been the most enforced to date.

In a broader sense, 'zoning' is the division of a city or county by legislative regulations into areas in order to specify permissible uses for real property and size restrictions for buildings within these areas - a program that implements policies of the general plan (Burack, Walls and Stewart, 2008). Originating from a court decision in Euclid, Ohio of the USA, single-use zoning, also known as Euclidean Zoning, was upheld as a necessary municipal planning instrument. Although the term 'land use zoning' implies regulation of uses, the underlying objective is to prevent various activities from interfering with one another in the use of land (Dukes, 2017).

However, zoning, as an activity segregation tool in the planning of cities, was questioned from the very early stages of its use. Jane Jacobs (1961) and Christopher Alexander (1965) were among the leading critics of mono-functional land uses enforced in modern, planned urban environments. While providing peaceful environments for those who do not want specific activities, preventive zoning leads to diseconomies of scale for activities in the absence of the required utility (Hoch, 1969). As a planning tool, the separation of activities into zones provides some technically sound benefits such as reducing traffic congestion, convenience to provide specialized infrastructure, etc., but it also leads to socially distractive, regimented, sterile environmental conditions which lack informal vitality. Zoning regulations include safety protocols to protect from fire and other hazards, but they do not include protection from crime and other social issues (Paulsen, 2013).

Increasing pressure against zoning and the legitimized urban environments resulting out of that, compelled planners to find a middle path between the segregation and integration of functionally different activities and to guide developments towards a right mix of uses in urban areas. However, deciding the right mix is not simple, because urban activities have a natural tendency to find locations most appropriate for their operations. They too have agency, behavior which is not fully amenable to the control of institutionalized planning processes or authoritative regulatory mechanisms. Hence, in order to get them organized in the desired direction, planners need to be sensitive to the natural self-organizing processes of urban activities and be more 'strategic' in their interventions to get them integrated into legitimate spatial strategies. Such endeavors highlight the need for studies on the processes by which different activities appropriate urban spaces for their operations.

\section{Preceding studies}

Literature on urban studies explain the growth and evolution of urban areas as an incremental agglomeration of economic activities; that is, frequent transactions among human actors and firms, engaged in producing various products and services, by locating themselves within relatively close proximities (e.g.: Glasser,1992). The location decisions that enabled the agglomerations of activities, however, are not arbitrary. Classical theories descending from Christaller's (1933) central place theory described them as a function of the 'threshold population' and the 'market ranges' approximated for each of the urban commodities. Theories emerging from urban sociology, led by E.W. Burgess's observations on the 'Concentric Zones' (Park et al., 1925) characterized by occupation of lands in and around the Central Business District of Chicago by different social groups, implied the underlying competition among different urban activities for spaces with specific spatial attributes such as proximity, centrality and connectivity. Alfred Webber (1929) explained that firms select specific locations for their industries with three objective functions, namely, minimizing 
transport costs, minimizing production costs and maximizing profits. Krugman (1993) defined two types of origin of the activities in the agglomeration - the 'first nature', that is, the offspring of a natural phenomenon such as a port or a mine, and the 'second nature', that is, a secondary accumulation and a growth around an activity initiated for some other purpose.

Although these theories provide insights into the factors that affect location decisions of urban activities, they emphasize less on the means by which such dynamics could be potentially integrated in devising spatial strategies for the planning of urban areas.

The Space Syntax method, introduced by Hiller and Hanson (1984) and further developed by Hillier (1996), addressed this gap, demonstrating the multiple relationships that inequality of spatial attributes, resulting from the overall configuration of public spaces (mainly streets and access-ways) in an urban area, have with their activity locations, pedestrian and traffic flows, level of attraction, etc. This approach spells out the dynamic process in which different spaces attract both people and activities into them as a function of 'movement economy' and 'spatial integration' (Hiller, 1996). The 'movement economy' concept explains that humans have an inherent habit of 'economizing' movement (by choosing the shortest possible path for movement between locations) and urban activities adapt to take maximum advantage of the movement of people (Hillier and Penn, 2004). In a subsequent study, Hillier et al. (2000) studied the relationship between the pattern of commercial activities, informal settlements and the spatial limitations of the built environments in Santiago (Hiller et. al, 2000), and in a recent study Shen and Karimi (2017) emphasized the complex interrelationships between the spatial network and land-use patterns in Cairo as the major determinants of the formation of urban function regions.

Hillier and Penn (2004) proposed that in space syntax theory, land use is a dependent variable; spatial configuration influences movement and, further, the formation of centers and sub-centers, can be expected to influence land uses. Hence, the investigation of the impact of spatial configuration on land uses serves for a theoretical understanding of cities as well as for the practical importance related to location choices of different activities.

Even though some persisting limitations in accounting for distance, scale and sinuous streetscapes, highlighted by critics (e.g.: Ratti, 2004), exist, Space syntax analysis has made major contributions to the understanding of the spatial structure of cities, particularly the importance of mapping of network integration in relation to density, functional mix and street life vitality, focusing the attention of urban researchers onto the importance of the relations between the sociality and spatiality of the city (Pafka et al., 2018) .

However, despite the relatively large body of progressive studies and wide applications of space syntax available around the world, only very limited work is recorded in the Sri Lankan context. Among them, The Evolution of the City by Bandara and Munasinghe (2007), was the first instance where space syntax was effectively used to study an urban environment in Sri Lanka. This work recorded the evolution of the City of Colombo in a systematic investigation of continuous changes observed in the land uses in different segments of the city corresponding to the changes in the overall configuration of urban spaces with the introduction of new accessways and public spaces and the integration of new quarters extending the boundaries of the city. In another study, Bandara et al. (2009) applied the method to compare the persistent growth in and around the historic center of the city of Ratnapura, resisting the annual flood damages, as opposed to shifting urban activities from the traditional center as in the city of Galle.

\section{Theoretical framework}

The activity distribution pattern in an urban area can be understood as an outcome of the balancing process between the location choices of different urban activity types and space appropriation by different forces that are in operation. In line with the propositions of widely acclaimed land use theories, it can be conceptualized that in a liberal environment, urban activities compete to find spaces which have the attributes that are most appropriate for their operations. Accessibility, centrality and visibility are among the topologically analyzed spatial attributes attractive to them. 
In this competition, relatively more profitable ventures acquire more economically and functionally advantageous locations in an urban environment.

According to Space Syntax theory, the competitive advantage of a given location is decided by the level of its 'spatial integration', resulted in by the axial connectivity of urban spaces. Thus, the first step in Space Syntax analysis is to reduce the composition of streets, alleyways and all other public spaces in an urban area into a composition of axial lines incidental either on one another or many others. The most economical path of movement in terms of the number of axial line connections (shortest possible path) that a person has to pass through to get to a space from another space, decides the level of connectivity of the first space in relation to the second. In this manner, the connectivity of a space into all other spaces in the urban area can be evaluated by accounting for its overall spatial configuration, and it reflects the degree to which each space is integrated into the urban area.

The method emphasizes two levels of integration of an urban space - local and global (Hillier, 1996). The local integration is indicative of the structural composition of public spaces at the locality level and its analysis enables to identify the locations that are most and least spatially integrated in the immediate context. Thus, the level of topological connectivity is relative within the local context but cab be normalized by means of spatial integration. The global integration is the indicator of the attractiveness of different public spaces at the overall spatial configuration of the city. When an urban area is analyzed at the local level, it is hypothesized that the local centers would emerge as the most integrated spaces and therefore, more competitive urban activity types would dominate the land uses in and around them. At the global level, the competition is between different segments of the city to attract more competitive uses into them, and the inequal levels of integration lead some centers to be overthrown by the more spatially integrated ones. As the city grows, the pattern of spatial configuration changes and the level of integration of individual locations too change. Thus, the attractive capacities fluctuate leading to a transformation of activity locations in the city.

In this study only the local integration is considered since the prime objective of this study is to examine the possible relationship between the distribution pattern of activity types and the varying spatial attributes of their locations.

\section{The Method}

Since the study uses instantaneous data, it is not possible to identify any causative relationship between the selected variables within the scope of this study. Therefore, the focus would be on the mutual interrelations between the two variables, rather than their dependency on each other.

The city of Colombo has been selected for the study partly due to its importance as the largest urban area in Sri Lanka, where planning interventions have throughout failed to effectively address the location incompatibilities of activities. On the other hand, it is due to the availability of the complex urban environment required for a study of this nature. The analysis of the interrelations was limited to the municipal boundaries of the City of Colombo, but in order to avoid the 'edge effect' in the analysis, the axial map was extended to a larger area in the city's metropolitan region.

As the first step, the urban activities distributed in the city area have been observed under a predetermined typology. For this purpose, the registers of the Urban Development Authority (UDA) of Sri Lanka was examined and out of many different activity types, a broader classification was developed based on the nature of the activity, the manner of operations and the types of goods and services provided to the public.

Nine major types that is commonly used for planning purposes have been noted:
a. Retail Trading
b. Wholesale Trading
c. Consumer Services
d. Financial and the related Services
e. Specialized Goods and Services
f. Institutions 
g. Industries and Warehouses

h. Residential

i. Other

A detailed inspection of the Municipal records enabled the identification of sub-classes within these main ones and thereby, the number of types could be increased to twenty-three. The list of these types is given in table 01 .

Table 01: Activity types and their sub-categories

\begin{tabular}{|l|l|}
\hline \multirow{5}{*}{ Activity Type } & Sub-category \\
\hline \multirow{4}{*}{ Retail Trading } & Textile and Fashion \\
\cline { 2 - 2 } & Stationeries \\
\cline { 2 - 2 } & Grocery \\
\cline { 2 - 2 } & Retail - Excl Grocery \\
\hline \multirow{5}{*}{ Consumer Services } & Wholesale \\
\hline \multirow{5}{*}{ Specialized Goods and Services } & Private Office \\
\cline { 2 - 2 } & Restaurant \\
\cline { 2 - 2 } & Automobile Services \\
\cline { 2 - 2 } & Health \\
\cline { 2 - 2 } & Filling Stations \\
\cline { 2 - 2 } & Other \\
\hline Financial and the related Services & Banks and Other Financial \\
\hline \multirow{5}{*}{ Residential } & Automobile Showrooms \\
\cline { 2 - 2 } & Furniture \\
\cline { 2 - 2 } & Branded \\
\cline { 2 - 2 } & Jewelry \\
\hline Other & School \\
\cline { 2 - 2 } & Religious Places \\
\hline \multirow{2}{*}{ Institutions } & Warehouse \\
\hline Industries and Warehouses & Apartments \\
\cline { 2 - 2 } & Single Houses - Excl Under Served \\
\cline { 2 - 2 } & Underserved Settlements \\
\hline \multirow{5}{*}{} & Other \\
\hline
\end{tabular}

In the second step, a random sample of one hundred (100) registrations were selected from each type. The sample size varied between one percent to twenty percent within the category, depending on the extensiveness of the number of registrations. The sample size was purely a decision related to convenience and may have limitations in terms of its representativeness.

In the third step, the location of each activity was recorded in a map, following the confirmation of its location as observed in a field visit. A few items of the sample had to be replaced with new entries due to the inactivity and non-availability of the registered activity at the time of observation. The locations of the activities subject to the analysis are given in figure 01 . 


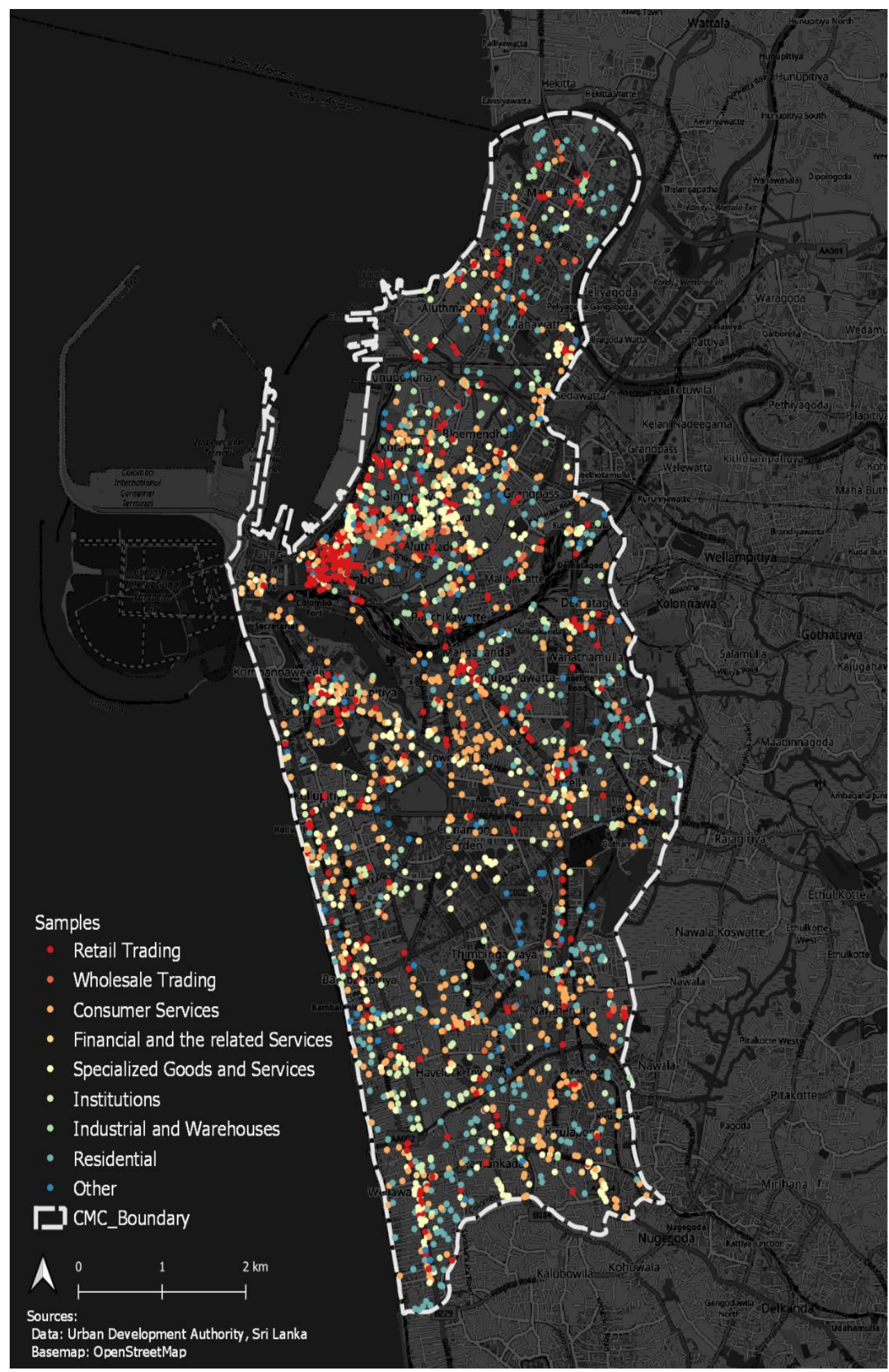

Figure 01: The locations of the sample activity units subject to this study

In the fourth step, the Space Syntax method was used to analyze the spatial configuration of the city of Colombo. The objective was to observe the 'spatial integration' value of the immediate location of the activity units. The integration values were observed both at 'local integration' ( $R_{3}$, Figure 02) and at 'global integration' ( $R n$, Figure o3), which are the widely used levels of analysis. 


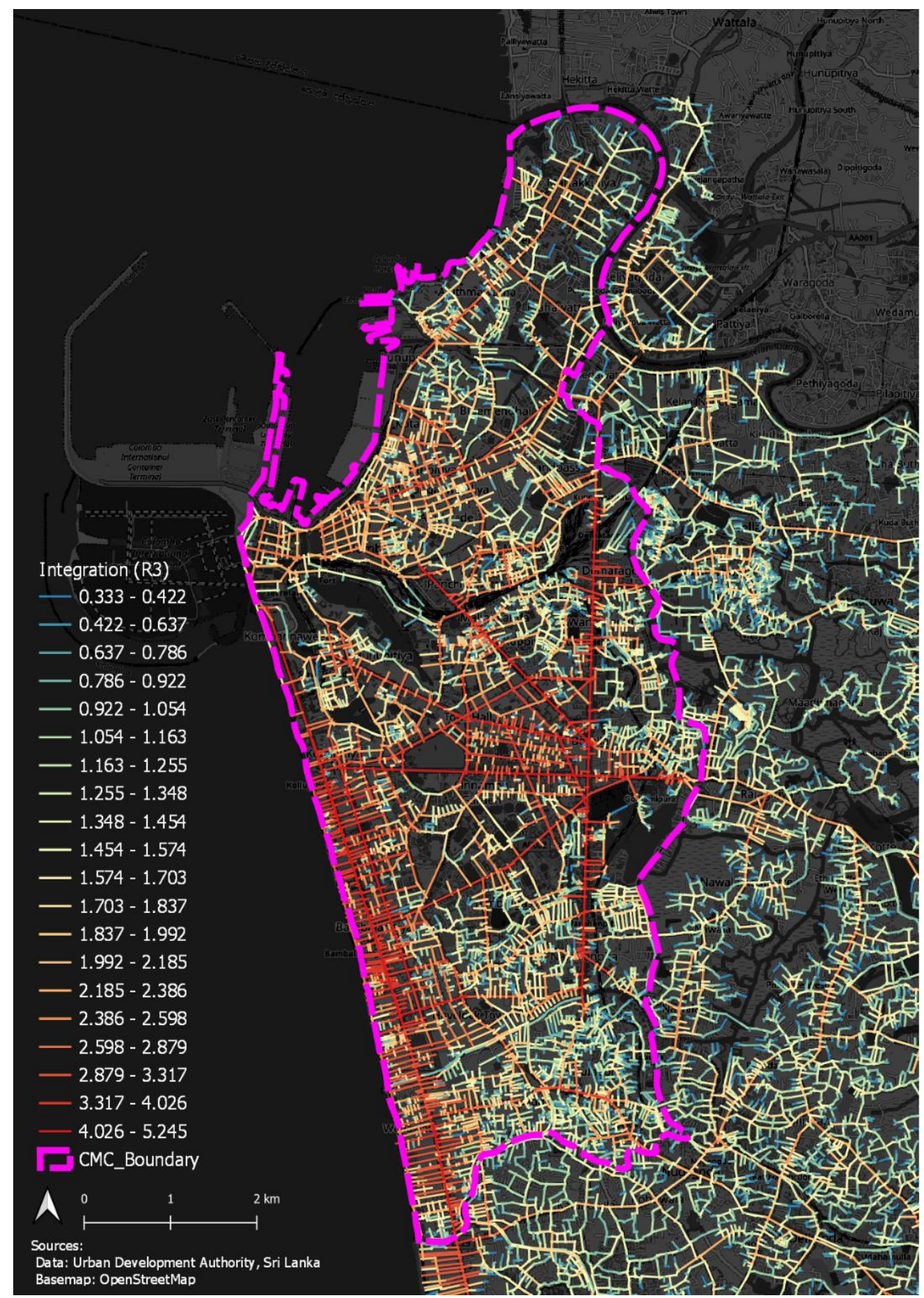

Figure 02: Analysis of Spatial Configuration: Local Integration (n3)

In the final step, the spatial integration values of all activity locations were recorded and examined for their statistical distribution. It is hypothesized that under liberal (non-regulated) conditions, the statistical mean and standard deviation of the integration values of the locations where the units of a particular activity type are located, reflect the levels of spatial integration preferred by those activity types for their smooth operation. 


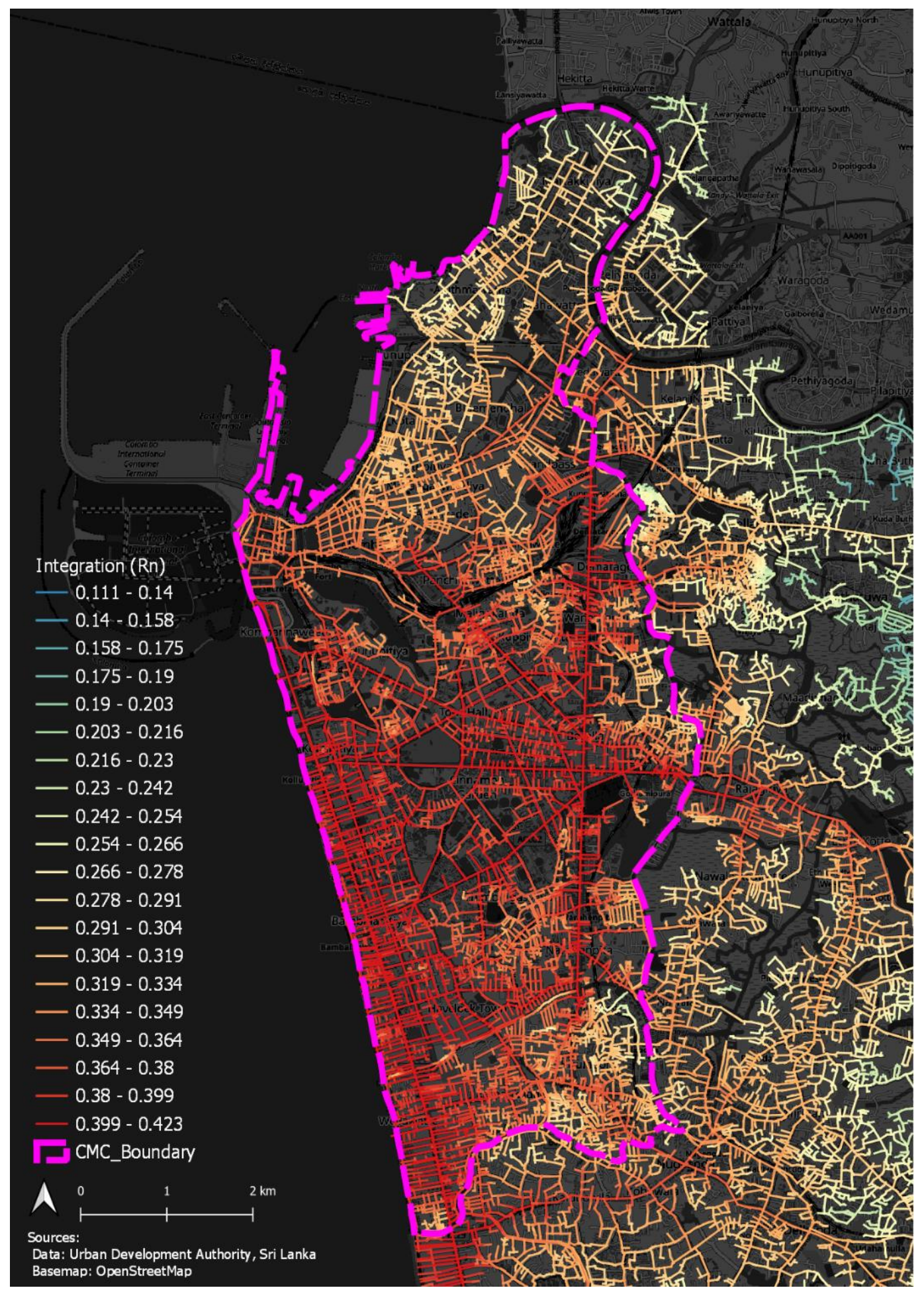

Figure 03: Analysis of Spatial Configuration: Global Integration (n)

\section{The Analysis and findings}

The statistical distribution of the spatial integration values of the activity locations, when plotted in their $\log _{10}$ values (SIV), exhibits a normal distribution as given in figure 04 , confirming the reliability of the sample. The SIVs of the twenty-three activity types, when plotted individually, also followed the same statistical distribution pattern, confirming the reliability within types. 


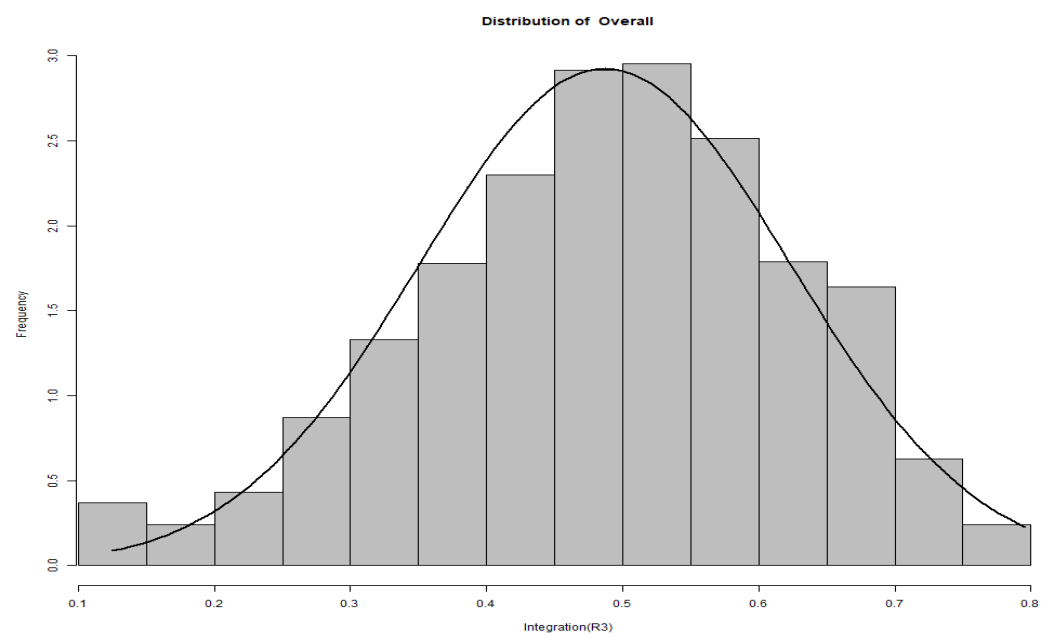

Figure 04: Statistical distribution of the spatial integration values (SIVs in $\log _{10}$ ) of all sample activity locations.

Figure 05 provides a summary of the distribution patterns of the SIVs across different activity types. The distribution of the SIVs of individual units within all activity types show a high level of consistency, where the standard deviation was within standard values. Such internal consistency implies that the environmental attributes resulting from the degree of spatial integration of urban locations is a latent consideration in the location choices of the firms who operate urban activities.

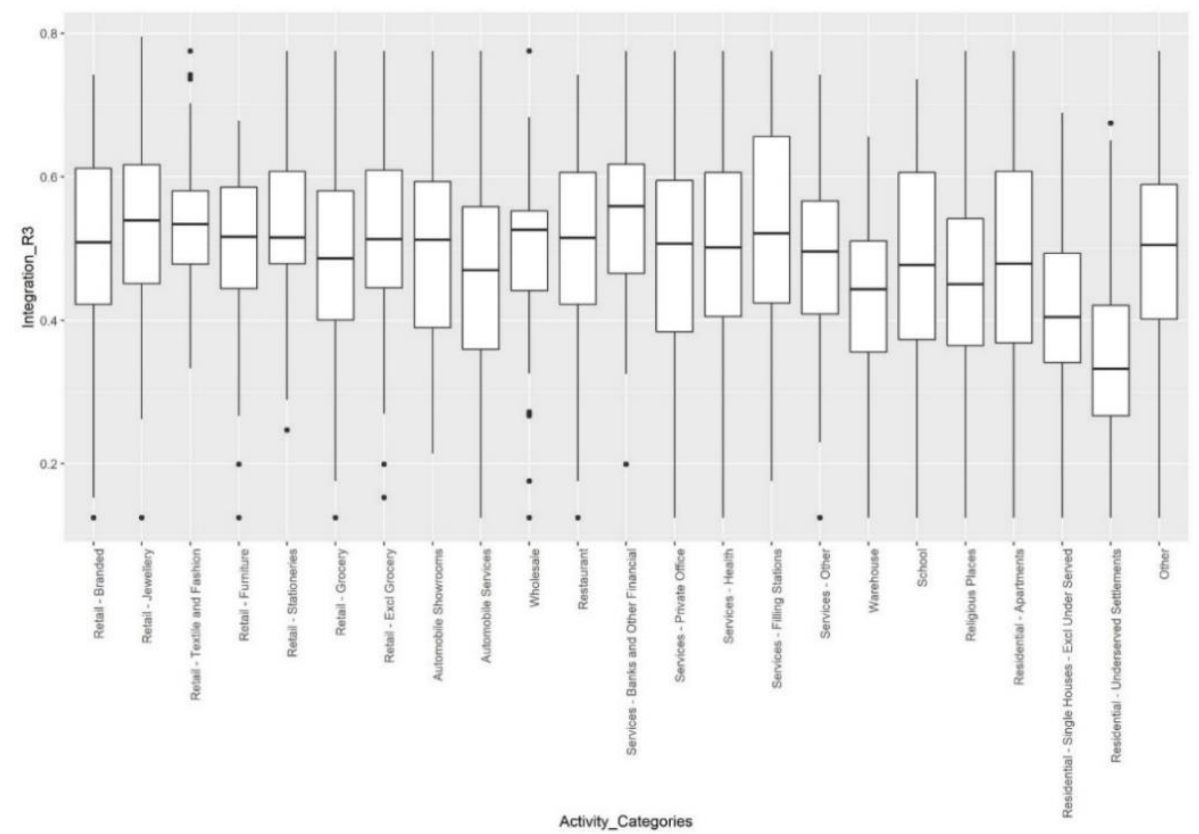

Figure 05: Box plot of the statistical distribution of SIVs of different activity types.

The means of the SIVs provided an observable hierarchy in the spatial distribution of the activity types. The Banking and Finance related activities are the predominant occupiers of the most spatially integrated locations in the City of Colombo, followed by other retail businesses. Residential and institutional activities (schools and religious places) occupy the least socially integrated locations.

At the same time, differences were observable among the statistical means of the SIVs of some activity types. On the premise that differences in SIVs reflect the variations in spatial attributes of locations in an urban area, this observation implies that the operators of activity types prefer specific spatial attributes of locations, when they exercise the location choice. In order to test the consistency and the reliability of this observation, the data set was subjected to a T-test. The T-test is a statistical process employed to determine any significant difference between the means of two sample 
populations (Berenson and Levine, 1996). Hence, a pairwise comparison was employed and the hypothesis (Ho) at this instance was that there would be significant differences among the statistical distributions (mean values) of the SIVs of different activity types.

Table 02: The degree of difference between the SIVs of activity types

\begin{tabular}{|c|c|c|c|}
\hline Activity Category & Mean & $\begin{array}{c}\text { No. of } \\
\text { categories that } \\
\text { mean is } \\
\text { significantly } \\
\text { different } \\
(x)\end{array}$ & $\begin{array}{c}\text { x/Total } \\
\text { Number } \\
\text { of } \\
\text { Categories } \\
\text { (\%) }\end{array}$ \\
\hline Retail - Branded & 0.5173953 & 8 & $34.78 \%$ \\
\hline Retail - Jewellery & 0.5407428 & 16 & $69.56 \%$ \\
\hline Retail - Textile and Fashion & 0.5390613 & 16 & $69.56 \%$ \\
\hline Retail - Furniture & 0.5012539 & 9 & $39.13 \%$ \\
\hline Retail - Stationeries & 0.5325590 & 15 & $65.22 \%$ \\
\hline Retail - Grocery & 0.4923181 & 8 & $34.78 \%$ \\
\hline Retail - Excl Grocery & 0.5209391 & 7 & $30.43 \%$ \\
\hline Automobile Showrooms & 0.5017417 & 8 & $34.78 \%$ \\
\hline Automobile Services & 0.4663775 & 12 & $52.17 \%$ \\
\hline Restaurant & 0.5061822 & 7 & $30.43 \%$ \\
\hline Wholesale & 0.4921898 & 8 & $34.78 \%$ \\
\hline Services - Banks and Financial & 0.5455050 & 17 & $73.91 \%$ \\
\hline Services - Private Office & 0.4945708 & 8 & $34.78 \%$ \\
\hline Services -Health & 0.5023711 & 7 & $30.43 \%$ \\
\hline Services - Filling Stations & 0.5268214 & 5 & $21.73 \%$ \\
\hline Services - Other & 0.4899807 & 8 & $34.78 \%$ \\
\hline Residential -Apartments & 0.4749440 & 9 & $39.13 \%$ \\
\hline Residential - Single Houses & 0.4073141 & 21 & $91.3 \%$ \\
\hline Residential - Underserved areas & 0.3312517 & 21 & $91.3 \%$ \\
\hline Warehouse & 0.4265894 & 20 & $86.96 \%$ \\
\hline School & 0.4707453 & 9 & $39.13 \%$ \\
\hline Religious Places & 0.4519866 & 12 & $52.17 \%$ \\
\hline Other & 0.4930798 & 7 & $30.43 \%$ \\
\hline
\end{tabular}

The results showed that out of 256 pairwise tests, 129 are significantly different at $95 \%$ confidence. In the interpretation, given in table 02, the distribution pattern of the spatial integration levels of the locations (SIVs) of all activity types show a difference from at least $30 \%$ of the other activities. The SIVs of nine types are significantly different to more than $50 \%$ of the other activities, while six types are different to more than $70 \%$ of the types.

\section{Discussion and Conclusion}

The results of the above can be interpreted relating to the objective of this study, i.e. to examine the possible relationship between the overall spatial configuration of the city of Colombo and the distribution pattern of its urban activities. The self-organizing of activities in an urban area is viewed as a function of the location choices of the firms or the operators of such activities and the inequality in spatial attributes of locations resulting from the overall spatial configuration of that urban area. Even though this mutual relationship between location choices and spatial attributes was discussed in previous theories, such relationships were not widely tested in a manner such that they could be progressively integrated into workable planning strategies. 
In that context, this study can have valid implications. While converging the findings of preceding studies in this area of research, it enhances the reliability of space syntax as a method that can be used for urban analysis in the Sri Lankan context. The method has been used in many countries to successfully model the relationship between the spatial configuration of physical environments and several important urban characteristics, such as existing hierarchies, pedestrian and vehicular traffic flows, activity distribution patterns and land uses and values. The two main observations of this study provide valid grounds to use the space syntax method to model the probable outcome of alternative spatial decisions in planning such as the construction of new roads, opening missing links between separated spaces, etc., in an urban area.

Urban planning is essentially a decision-making process and planning decisions are mostly intuitive and inherently bound by risks, to the extent that planners work with imperfect information and value laden societies. In order to avert risks, planning professionals must be cautious, and wider public participation, expert consultation and consideration of alternatives are recommended. However, these options are limited in their predictive capacity, since they all must operate within limited foreseeable future causes of action. In order to fill this gap, space syntax provides planners with a more technically sound method that can be employed to simulate the outcome of a planning decision that affects the existing state of the physical environment of a city.

This study was initiated to cater to the need for a more comprehensive understanding on urban dynamics that organizes different activities in an urban area, which is important for planners to make strategic decisions. This study provided grounds for that purpose by examining the relationship between the spatial attributes that appropriated location choices of different urban activities.

Despite the consistency of the results, the sample of the urban activities selected for this study can be questioned for its representativeness in some categories. Therefore, further studies may be required, which extend the number of activity locations with a larger sample. The study is also limited as it analyzed an instantaneous relationship. Further studies could take into account the periodic changes in the activity patterns in order to examine the causative relationship between the two variables.

\section{Acknowledgement:}

This research was supported by the grant no. SRC/ST/2013/o6, of the Senate Research Committee of the University of Moratuwa, Sri Lanka.

\section{References}

Alexander, C., 1965, A City is Not a Tree. Architectural Forum, Vol 122(01), pp 58-62

Bandara, A and Munasinghe, J, 2007, Evolution of a City: a Space Syntax approach to explain the spatial dynamics of Colombo, Proceedings of the $7^{\text {th }}$ Congress of the Asian Planning Schools Association (APSA), pp 28- 39

Bandara, A, Meetiyagoda, L and Munasinghe, J, 2010, Spatial Configuration as a Determinant of the Activity Pattern: The Case of two Small Cities in Sri Lanka, Bhúmi, The Planning Research Journal, 02(02), pp 12-21

Bereson, M and Levine D M, 1996, Basic Business Statistics: Concepts and Applications (6 ${ }^{\text {th }}$ Edition), London: PrenticeHall International Inc.

Burack, T S, Walls, M J and Stewart P E H, 2008, Innovative Land Use Planning Techniques: A handbook for sustainable development, New Hampshire Department of Environmental Services.

Christaller, W., 1933. Die Zentralen orte in sudden deutschland (Central places in Southern Germany). New Jersey: Prentice Hall.

Dukes, A., 2017, A Town Well Planned: Hierarchical Zoning. [Online] Available at: https://www.strongtowns.org/journal/2017 /8/29/a-town-well-planned-hierarchical zoning

Glaser, E.L., Kallal, H.D., Scheinkman, J.A., and Shleifer, A., 1992, Growth in cities, Journal of Political Economy, 100(6), pp 1126-1152

Hillier, B., 1996, Space is the machine: A configurational theory of architecture, Cambridge University Press, Cambridge.

Hillier, B., and Hanson, J., 1984, The Social Logic of Space, Cambridge: Cambridge University Press

Hillier, B., Greene, M., Desyllas, J., 200o, Self-generated Neighbourhoods: the role of urban form in the consolidation of informal settlements, Urban Design International Vol 5, pp 61- 96

Hillier, B. and Penn, A., 2004, Rejoinder to Carlo Ratti, Environment and Planning B: Planning and Design, vol. 31, pp 501-511.

Hoch, I., 1969, The three-dimensional city: Contained urban space, in The Quality of the Urban Environment, Essays on "New Resources" in an Urban Age, Edited by Harvey, S P, Baltimore: John Hopkins Press, pp 74-106 
Jacobs, J., 1961, The Death and Life of Great American Cities, New York: Random House.

Krugman, A., 1993, First nature, second nature and metropolitan location, Journal of Regional Science, 33(2), pp 129144 .

Marcus, L., 2007, Spatial Capital and How to Measure it: An Outline of an Analytical Theory of the Social Performativity of Urban Form, Proceedings of 6th International Space Syntax Symposium, Istanbul, pp.005/1005/12.

Pafka, E., Dovey, K. and Aschwanden, Gideon D.P.A., 2018, Limits of space syntax for urban design: Axiality, scale and sinuosity, Environment and Planning B: Urban Analytics and City Science, 47(3), pp 508-522

Park, R. E., Burgess, E. W., \& McKenzie, R. D. (1925). The city. Chicago, Illinois: The University of Chicago Press.

Paulsen, D. J., 2013, Crime and Planning: Building Socially Sustainable Communities, Chicago: American Planning Association Press

Ratti, C., 2004, Space syntax: Some inconsistencies, Environment and Planning B: Planning and Design, vol. 31, pp. 487- 499.

Shen Y. and Karimi, K., 2017, Urban evolution as a spatio-functional interaction process: the case of central Shanghai, Journal of Urban Design, 23(01)

Webber, A, 1929, Alfred Weber's theory of the location of industries, The University of Chicago Press 